\title{
Glutamate Carboxypeptidase II Gene Expression in the Human Frontal and Temporal Lobe in Schizophrenia
}

\author{
Subroto Ghose', Cynthia Shannon Weickert', Sarah M Colvin', Joseph T Coyle ${ }^{2}$, Mary M Herman', Thomas \\ M Hyde' and Joel E Kleinman*,' \\ 'Clinical Brain Disorders Branch, IRP, NIMH, NIH, Bethesda, MD, USA; ${ }^{2}$ McLean Department of Psychiatry, Harvard Medical School, Belmont, \\ MA, USA
}

\begin{abstract}
There is decreased activity of glutamate carboxypeptidase II (GCP II) in the dorsolateral prefrontal cortex (DLPFC) and hippocampus of patients with schizophrenia. GCP II hydrolzses $N$-acetyl- $\alpha$ L-aspartyl-L-glutamate (NAAG), a peptide in the mammalian brain that binds to the N-methyl D-aspartate (NMDA) receptor and a group II metabotropic glutamate receptor, both of which have been implicated in the pathophysiology of schizophrenia. We examined the expression of GCP \| mRNA in the DLPFC, entorhinal cortex (ERC), and hippocampus in postmortem samples from patients with schizophrenia and normal controls using in situ hybridization followed by silver grain detection. GCP II mRNA was detected in glial cells. Glial-rich regions, specifically the DLPFC and ERC white matter and the molecular and polymorphic layers in the hippocampus, express high levels of GCP II mRNA. Given the earlier finding of decreased GCP II activity in brains of subjects with schizophrenia, we expected to find lower GCP II mRNA levels in schizophrenia. Contrary to this expectation, we found a significantly higher expression of GCP || mRNA in one of the brain areas examined, the hippocampal CA3 polymorphic region. This may reflect a compensatory increase to correct for the decreased activity of GCP II activity. Our findings support the notion that the hydrolysis of NAAG is disrupted in schizophrenia and that specific anatomical regions may show discrete abnormalities in GCP II synthesis.

Neuropsychopharmacology (2004) 29, I I7-125, advance online publication, 15 October 2003; doi: I0. I038/sj.npp. I 300304
\end{abstract}

Keywords: NAALADase; NAAG; CA3; polymorphic; glia; mRNA

\section{INTRODUCTION}

Glutamate, the major excitatory neurotransmitter in the mammalian brain, has been implicated in the pathophysiology of schizophrenia (reviewed in Tsai and Coyle, 2002). However, the precise nature of this abnormality has not been elucidated, partially because regulation of glutamate synthesis, release, receptor activation, and glutamate breakdown is complex and often difficult to study directly at sufficient spatial and temporal resolution in patients with schizophrenia. One important discovery implicating glutamate receptors is the finding that antagonists of the $\mathrm{N}$ methyl-D-aspartate (NMDA) receptor, phencyclidine (PCP; Javitt and Zukin, 1991), and ketamine (Krystal et al, 1994) can cause positive, negative, and cognitive symptoms resembling schizophrenia in healthy individuals and can

\footnotetext{
*Correspondence: Dr JE Kleinman, Clinical Brain Disorders Branch, $\mathrm{NIMH}, \mathrm{NIH}, 9000$ Rockville Pike, BIdg I0, Rm 4S 237A, Bethesda, MD 20892, USA, Tel: 30 I 402 7908; Fax: 301480 7795;

E-mail: kleinmaj@intra.nimh.nih.gov

Received OI May 2003; revised 30 June 2003; accepted 04 August 2003

Online publication: 8 August 2003 at http://www.acnp.org/citations/ Npp08080303 | 86/default.pdf
}

exacerbate psychotic symptoms in patients with schizophrenia (Lahti et al, 1995, 2001). By blocking a subpopulation of NMDA receptors, the dissociative anesthetics, like PCP, increase glutamate release in the prefrontal cortex and nucleus accumbens in rodents, producing behaviors that mimic the schizophrenic state, such as increased locomotor activity, stereotypies, and impaired performance on working memory tasks (Moghaddam and Adams, 1998). The pretreatment of these animals with a group II metabotropic glutamate receptor agonist (group II mGluR), LY 354740, prevents the glutamate efflux and abolishes some of the PCP-induced behaviors. Another potent mGluR2/3 receptor agonist, LY 379268, has been shown to attenuate selectively PCP-evoked increases in motor activity in a manner similar to the effect of the atypical antipsychotic, clozapine (Cartmell et al, 2000). Taken together, these data suggest the involvement of NMDA receptors and group II mGluRs in the pathophysiology of schizophrenia.

An endogenous peptide, $N$-acetylaspartateglutamate (NAAG) targets both the NMDA receptor and one of the group II mGluRs, that is mGluR3. It may function as a weak agonist at NMDA receptors (Westbrook et al, 1986; Trombley and Westbrook, 1990; Sekiguchi et al, 1992), and is a highly selective agonist at mGluR3 receptors 
(Wroblewska et al, 1998). NAAG is the most prevalent and widely distributed neuropeptide in the mammalian nervous system (reviewed in Coyle, 1997; Neale et al, 2000). It meets criteria for classification as a neurotransmitter, being concentrated in synaptic vesicles (Williamson and Neale, 1988a; Renno et al, 1997) released in a calcium-dependent manner upon depolarization (Williamson and Neale, 1988b; Tsai et al, 1990), and is hydrolyzed by membrane-bound peptidase. Immunocytochemical studies reveal colocalization of NAAG in many putative glutamatergic pathways in the human brain (Passani et al, 1997). Glutamate carboxypeptidase II (GCP II; previously known as $N$-acetyl- $\alpha$-linked acidic dipeptidase, NAALADase) is one enzyme that cleaves NAAG to $N$-acetylaspartate (NAA) and glutamate (Slusher et al, 1990).

Activity of GCP II determines the relative extracellular levels of NAAG and glutamate (Stauch-Slusher et al, 1989). NAAG has predominantly inhibitory actions by virtue of its possible weak agonist activity at the $N$-methyl-D-aspartate receptor, blocking the gating of the channel by endogenous glutamate, with agonist activity at the mGluR3 receptor that is negatively linked to cAMP (Neale et al, 2000). There is evidence of decreased activity of GCP II in the PFC (-37\%) and hippocampus $(-28 \%)$, with decreased glutamate levels in these regions, and increased NAAG levels in the hippocampus of the schizophrenic brain compared to normal controls (Tsai et al, 1995). In vivo, magnetic resonance spectroscopic imaging has revealed selective reductions in NAA in the dorsolateral prefrontal cortex (DLPFC) and hippocampus in schizophrenia (Bertolino et al, 1996; Deicken et al, 1999). Additionally, the GCP II gene is in proximity to the breakpoint region in chromosome 11 of the schizophrenia-linked translocation $\mathrm{t}(1: 11)$ (q42.1, q14.3) (Semple et al, 2001), suggesting its candidacy as a susceptibility gene for schizophrenia.

This study was performed with the aim to elucidate the cell specificity and expression pattern of GCP II mRNA in the DLPFC and mesial temporal cortex in the normal primate brain, and to compare levels of expression to patients with schizophrenia. Our initial hypothesis, based on findings of decreased GCP II activity in schizophrenia, was that there is a decrease in GCP II mRNA levels in schizophrenia. As discussed later in the paper, we found an increase in GCP II mRNA levels in a specific hippocampal region.

\section{RESULTS}

\section{DLPFC}

Cohort 1 , consisting of subjects with schizophrenia and normal controls, was used to perform the analysis of GCP II mRNA in the DLPFC (Table 1). We did not find significant differences between these two groups in terms of age $\left(\mathrm{df}_{1,27}\right.$, $p=0.89), \mathrm{pH}\left(\mathrm{df}_{1,27}, p=0.90\right)$, or postmortem interval (PMI; $\left.\mathrm{df}_{1,27}, p=0.11\right)$. There were no significant correlations between GCP II mRNA and any of the demographic variables $(\mathrm{pH}, \mathrm{PMI}$, age, lifetime exposure to antipsychotic medication) analyzed (all $R$ between -0.09 and 0.24 , all $p>0.2$ ).

The normal distribution of GCP II mRNA in the DLPFC was examined in humans and monkey sections using in situ hybridization. GCP II mRNA hybridization signal from the autoradiographic films was found in a similar distribution in monkey and human brain. In the human, the GCP II mRNA signal was detected in gray matter areas of the middle frontal gyrus, but was more intense in the underlying white matter. Similarly, the GCP II signal in the monkey was low in gray matter areas along the bank of the principle sulcus, but was more intense in the underlying white matter (Figure 1a,b). This finding suggests that nonneuronal cells that are predominantly found in the white matter, such as astrocytes and/or oligodendrocytes, may be the primary sites of synthesis of GCP II in the primate brain. Silver grain analysis, performed in the monkey sections, revealed that silver grains corresponding to GCP II mRNA were clustered over cells with a glial profile and were absent over neurons (Figure 1c,d). The GCP II silver grains found overlying cells with small nuclei that were stained with Nissl supports the conclusion that GCP II synthesis occurs predominantly in glia, either astrocytes or olidodendrocytes, rather than in neurons. GCP II mRNA is known to be expressed in cells that coexpress glial fibrilliary acidic protein (GFAP) and an astrocyte-specific glutamate transporter, GLAST (Berger et al, 1999), suggesting that GCP II mRNA is expressed primarily by astrocytes. The expression pattern described for GCP II mRNA in the DLPFC in both gray and white matter was similar in both normal controls and patients with schizophrenia. The mixed model ANOVA did not show a main effect of diagnosis $\left(\mathrm{F}=0.41, \mathrm{df}_{1,27}\right.$, $p=0.53$ ) on GPC II mRNA levels in DLFPC of patients with schizophrenia compared to controls. However, as expected, there was a main effect of area with higher levels of GCP II mRNA in white matter compared to gray matter $(\mathrm{F}=65.12$, $\left.\mathrm{df}_{1,27}, p<0.001\right)$. The interaction between diagnosis and region was not significant $\left(\mathrm{F}=0.38, \mathrm{df}_{1,27}, p=0.54\right)$. The removal of cases with highest PMIs (cases S6 and S7) resulted in a more closely matched cohort (age $\left(\mathrm{df}_{1,25}\right.$, $p=0.58) ; \mathrm{pH}\left(\mathrm{df}_{1,27}, p=0.2\right.$; PMI df $\left.1_{1,25}, p=0.40\right)$. Analysis with this cohort also did not show any significant effect on GCP II mRNA levels in the PFC between the two diagnostic groups (effect of diagnosis $\mathrm{F}=0.44, \mathrm{df}_{1,25}, p=0.51$; effect of area $\mathrm{F}=53.7, \mathrm{df}_{1,25}, p<0.001$; interaction between diagnosis and area $\mathrm{F}=0.65, \mathrm{df}_{1,25}, p=0.43$ ).

\section{Hippocampal Region}

Cohort 2 consisting of two groups, subjects with schizophrenia and normal controls, was used to examine the GCP II mRNA expression in the hippocampus. Using a $t$-test, there was no significant difference between the two groups for age $\left(\mathrm{df}_{1,19}, p=0.96\right), \mathrm{pH}\left(\mathrm{df}_{1,19}, p=0.89\right)$, or PMI $\left(\mathrm{df}_{1,19}\right.$, $p=0.17$ ). Correlations were seen in GCP II mRNA levels and $\mathrm{pH}$ (all $R$ between 0.05 and 0.64, all $p>0.002$ ). No significant correlations between GCP II mRNA levels and PMI or age were detected.

GCP II mRNA was detected in all mesial temporal lobe sections examined from both patients and controls (Figure 2a, 3). In the dentate gyrus and Ammon's horn of the hippocampus, GCP II mRNA was abundant in the polymorphic layer (Figure 2a, arrow) as well as near the pial surface of the fused hippocampal fissure (Figure 2a arrowhead), while expression within the granule cell layer and pyramidal neuronal layer was minimal. In fact, the 
Table I Demographics of Subjects

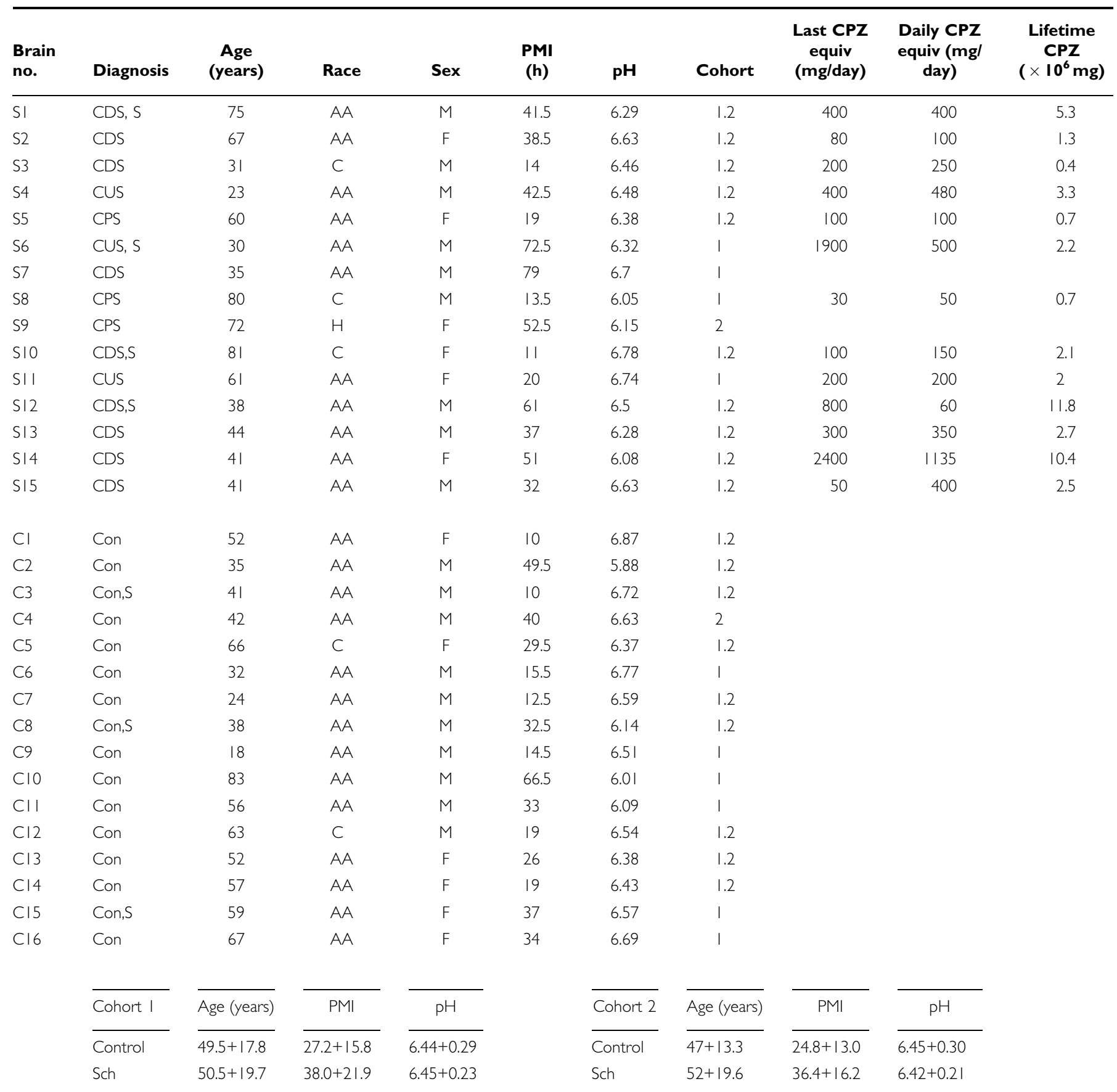

$\mathrm{PMI}=$ postmortem interval; $\mathrm{Dx}=$ diagnosis; $\mathrm{AA}=$ African American; $\mathrm{C}=$ Caucasian; $\mathrm{H}=$ Hispanic; Con = normal control; $\mathrm{CDS}=$ chronic disorganized schizophrenia; CPS = chronic paranoid schizophrenia; CUS = chronic undifferentiated schizophrenia; $S=$ comorbid substance use; CPZ = dose of antipsychotic medication in chlorpromazine equivalents; daily $C P Z=$ average daily dose; last CPZ = last known dose taken; lifetime $C P Z=$ total amount taken over lifetime.

expression pattern was inverse to that typically seen in the hippocampus with other RNA probes that hybridize strongly to neurons. Microscopic evaluation demonstrated the presence of GCP II mRNA over glial cells (Figure 2c). Highest density of signal of GCP II mRNA was found in Ammon's horn in a band curving along the ventricular surface; this polymorphic layer is enriched with astroglial cells and the increased hybridization signal found here is consistent with a predominately glial localization of GCPII
mRNA (Du et al, 1990). In further support of the glial localization of GCP II mRNA, silver grains were clustered over glial cell nuclear profiles (Figure 2e). A similar distribution was seen in the subiculum where the highest GCP II mRNA signal was detected in the superficial outer layer. In the entorhinal cortex, GCP II mRNA was higher in the white matter compared to the gray. This regional difference in GCP II mRNA levels was seen in both diagnostic groups. The comparison of GCP II distribution 

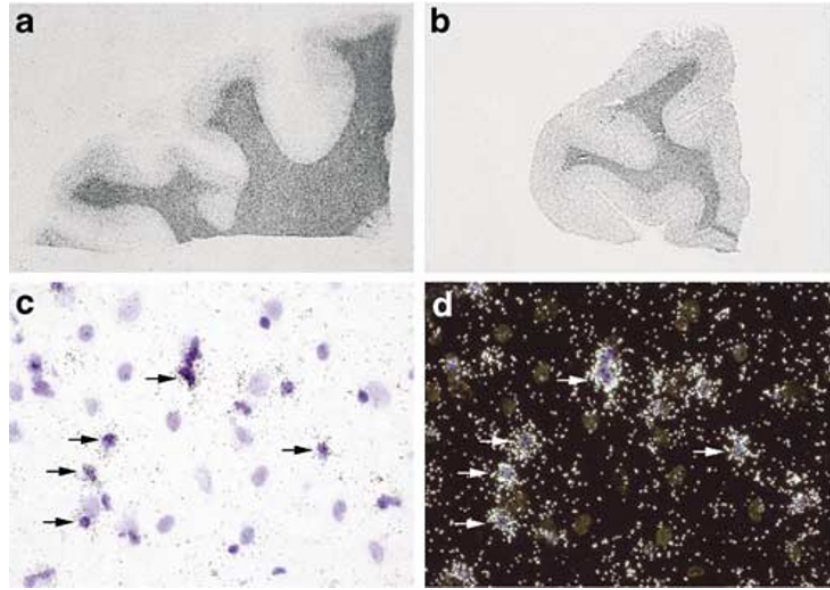

Figure I Autoradiographs (a, b), bright field (c), and dark field (d) photomicrographs of tissue sections from DLPFC of normal control subject (a) and monkey (b-d) following in situ hybridization with cDNA probes for GCP || showing glial localization of GCP I| mRNA (arrows).
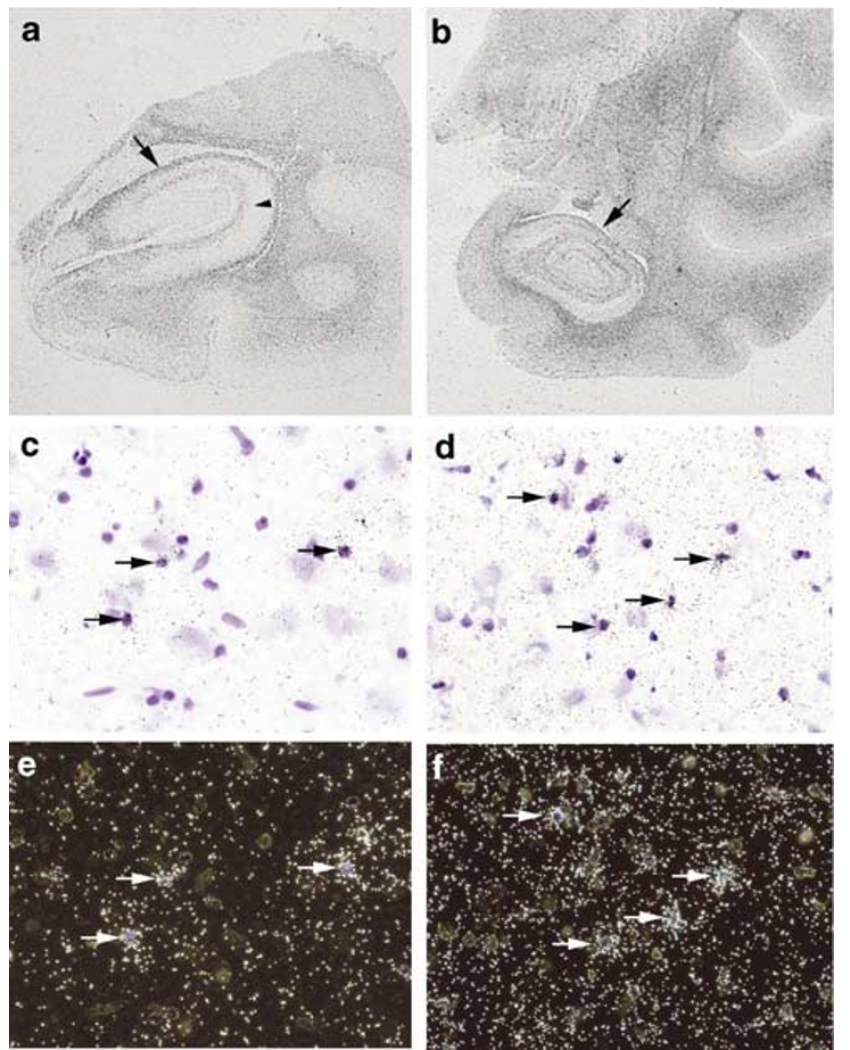

Figure 2 Autoradiographs (a, b), bright field photomicrographs (c, d), and dark field $(e, f)$ of tissue sections from midbody level of the hippocampus from a normal control subject $(a, c, e)$ and monkey $(b, d, f)$ following in situ hybridization with cDNA probes for GCP II showing its localization to glia (arrows).

in the mesial temporal lobe of monkeys revealed a pattern of expression similar to that in the human (Figure 2b). At the cellular level, silver grains were localized to glial cells in both humans and monkeys (Figure 2c-f).

We tested whether GCPII mRNA levels differed in the hippocampus of patients with schizophrenia vs controls. While we did not detect a main effect of diagnosis $(\mathrm{F}=1.81$,

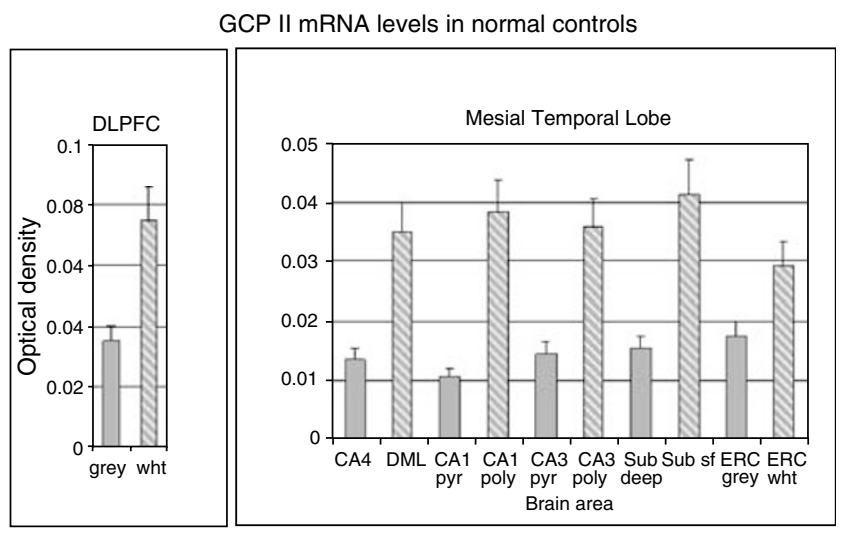

Figure 3 Mean GCP $\|$ mRNA levels in the subregions of the mesial temporal lobe and DLPFC in a normal control. DML = molecular layer of dentate gyrus, $C A \mid$ pyr = pyramidal layer of CAI, CAI poly= polymorphic layer of CAI, CA3 pyr = pyramidal layer of CA3, CA3 poly= polymorphic layer of CA3, Sub deep = pyramidal layer of subiculum, Sub sf = superficial/ outer layer of subiculum, ERC gray= entorhinal cortex, gray matter, ERC white = entorhinal cortex, white matter; DLPFC gray = dorsolateral prefrontal cortex, gray matter, DLPFC white=dorsolateral prefrontal cortex, white matter. Hatched bars indicate glia-rich regions.

$\left.\mathrm{df}_{1,12}, p=0.20\right)$, we did detect a significant main effect of area $\left(\mathrm{F}=24.34, \mathrm{df}_{1,117}, p<0.001\right)$ and a significant interaction between diagnosis and region $\left(\mathrm{F}=2.63, \mathrm{df}_{1,117}\right.$, $p=0.008)$. This result was followed up with post hoc $t$-tests, which showed that GCP II mRNA levels were significantly higher in the CA3 polymorphic layer in patients with schizophrenia compared to controls (Figures 4 and $\left.5 ; t=3.06, \mathrm{df}_{1,16}, p=0.0075\right)$. Since correlations were seen between GCP II mRNA levels and pH, an ANOVA with $\mathrm{pH}$ as the covariate was performed between GCP II levels in CA3 polymorphic layer and diagnosis. A significant increase in patients with schizophrenia was also found when $\mathrm{pH}$ was covaried $\left(\mathrm{F}=9.88, \mathrm{df}={ }_{1,15}, p=0.0067\right)$. Levels of GCP II mRNA in the CA3 polymorphic layer were $197 \%$ of normal controls while in every other region analyzed (including the dentate gyrus, CA4, CA1, subiculum and entorhinal cortex), GCP II mRNA levels were between 73 and 119\% of control levels (Figure 5) but did not reach statistical significance (all $t$ between -1.26 and 0.67 , all $p>0.22$ ).

We also did post hoc studies to examine further the significant main effect of brain area. Of all the regions investigated, the polymorphic layers of CA1 and CA3 and the superficial layer of the subiculum expressed the highest levels of GCP II mRNA. There was no difference in GCP II mRNA between these regions. However, the entorhinal cortex expressed significantly lower GCP II mRNA levels compared to these three regions $(p=0.007-0.04)$. There were no significant differences in GCP II mRNA levels between neuron-dense regions in the mesial temporal lobe, namely between CA4, pyramidal layers of CA1 and CA3, and the deep subiculum or ERC gray matter.

\section{DISCUSSION}

\section{Normal Distribution of GCP II}

In this study, we have characterized the distribution pattern of GCP II mRNA in two cortical areas, DLPFC and ERC, and 
GCP $\|$ mRNA in the

CA3 polymorphic layer

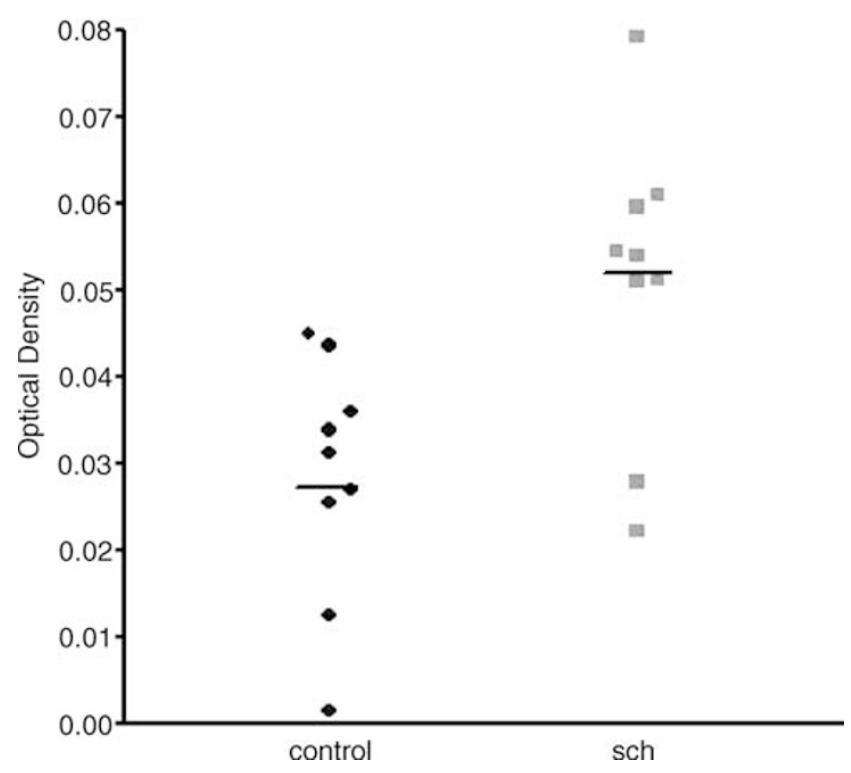

Figure 4 Scatterplot showing distribution of film-based measurements of GCP II message in the CA3 polymorphic layer in patients with schizophrenia and normal controls.

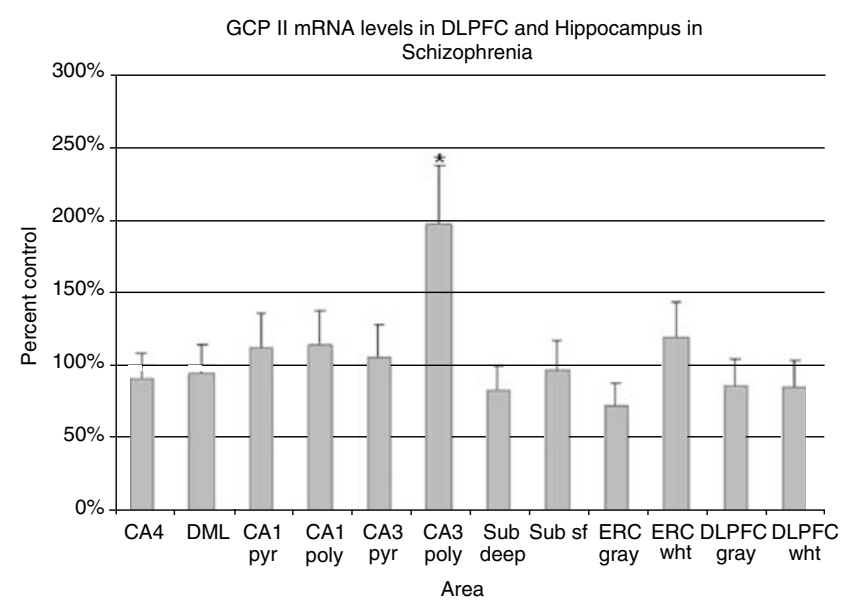

Figure 5 GCP \|| mRNA expression in various regions in the mesial temporal lobe and DLPFC expressed as a percentage of levels in matched normal controls. Levels in CA3 polymorphic region (*) are significantly higher in patients with schizophrenia compared to normal controls.

in subregions of the hippocampus. In all brain areas examined, expression of GCP II mRNA occurs primarily over glial cells, presumably astrocytes, while both pyramidal and nonpyramidal neurons are devoid of any message. These findings are consistent with reports in the rodent where GCP II mRNA colocalizes with the astrocytic marker, GFAP, and with Schwann cells but not neurons (LuthiCarter et al, 1998a, b; Berger et al, 1999). Additionally, GCP II immunoreactivity in the rat hippocampus was enriched in synaptic-rich neuropil, while no intracellular staining was detected in pyramidal cells or their dendrites (Slusher $e t$ al, 1992). Collectively, these data suggest that GCP II is expressed by astrocytes. Astrocytic endfeet wrap around neuronal synapses (Harris and Rosenberg, 1993), placing GCP II at a location where it can perform its role in cleaving NAAG. Immunohistochemical human studies have revealed intense NAAG-like immunoreactivity (NAAG-LI) in pyramidal neurons and interneurons in the CA1-CA4 regions (Passani et al, 1997), suggesting that NAAG, a peptide that meets criteria for a neurotransmitter, may be released at pyramidal and interneuron terminals. This released NAAG may be metabolized into NAA and glutamate by the glialderived GCP II. Indeed, glia are known to play instrumental roles in the metabolism and reuptake of many synaptically released neurotransmitters.

\section{GCP II in Schizophrenia}

Decreased GCP II activity in the DLPFC and hippocampus has been reported in schizophrenic subjects (Tsai et al, 1995). However, we did not find any difference in GCP II mRNA levels in the DLPFC between normal controls and schizophrenic subjects. This suggests that the decreased GCP II activity may not be due to decreased expression of the GCP II transcript. Contrary to our initial hypothesis, we found a nearly two-fold increase (197\%) in GCP II mRNA expression in the CA3 polymorphic layer in patients with schizophrenia.

The increase in GCP II mRNA levels is seen only in the CA3 polymorphic layer. The CA3 is a region selectively implicated as a specific site of pathology in schizophrenia in several studies. These have included reports of decreased AMPA and KA receptor subunits (Eastwood and Harrison, 1995a; Porter et al, 1997), decreased NMDA receptor binding (Dean et al, 1999), decreased excitatory aminoacid transporter 3 (EAAT3) mRNA (Bachus et al, 1996), and reduced levels of synaptophysin (Eastwood et al, 1995b, 1999; Webster et al, 2001). It is interesting to note that these findings are observed in the CA3 region, while the adjacent CA1 is devoid of these neuropathological changes, suggesting a selective vulnerability of the CA 3 region.

The CA3 polymorphic layer is comprised of basal dendrites from pyramidal neurons, interneurons, and glia (Amaral and Insausti, 1990; McBain and Fisahn, 2001). Principal axons of the CA3 pyramidal neurons give rise to primary branches, many of which remain in the polymorphic layer and arborize extensively (Li et al, 1994). It is estimated that $42-51 \%$ of the total dendritic length of a CA3 pyramidal neuron in the rat is located in the polymorphic layer (Ishizuka et al, 1995), and that the majority of boutonladen collaterals are found in the polymorphic layer $(64 \%$ in the study by Sik et al, 1993). Within this layer there are three types of interneurons (oriens-lacunosum-moleculare (O-LM) interneuron, basket cells, and bistratified cells) that show domain-specific innervation of the pyramidal neuron. For example, O-LM interneurons project to distal dendrites of pyramidal neurons, while basket cells project to the pyramidal neuron soma and proximal dendrites (reviewed in McBain and Fisahn, 2001). The majority of contacts made between the CA3 pyramidal neurons and GABAergic neurons are in the polymorphic layer (63\% in the study by Sik et al, 1993). Synapses in the CA3 region at which NAAG may modulate neurotransmission include those between CA3 neurons, between GABAergic neurons, and 
between the CA3 neuron and GABAergic neuron (Figure 6). We can speculate that alterations in GCP II mRNA may lead to specific changes in GCP II activity and to very localized changes in NAAG and NAA concentrations. Altered NAAG levels at synapses in the CA3 polymorphic layer could result in the disruption of the recurrent inhibitory feedback/feed forward function that would impair the ability of the CA3 field, as a whole, in modifying incoming information and transferring the modified message to the CA1 field.

The reasons for the discrepancy between the present findings with quantitative in situ hybridization for GCP II mRNA and those of the previous study in which GCP II activity was measured in postmortem tissue is unclear. It is possible that the increase in GCP II mRNA levels may reflect a compensatory response to normalize low GCP II enzyme activity. Further studies to quantify protein levels of GCP II in the CA3 polymorphic region may help address this issue. Alternatively, the difference between the previous and this study may reflect heterogeneity in the etiology of schizophrenia. In the earlier study showing decreased GCP II enzyme activity in schizophrenia, only $40 \%$ of subjects exhibited marked reductions in enzyme activity. Thus, only a subgroup of patients with schizophrenia may suffer from a reduction of GCP II activity. A third explanation for the difference may be the heterogeneity in the response to medications among patients in the two studies. Recent preclinical research reveals that both dissociative anesthetics such as phencyclidine and the antipsychotic, haloperidol, increase expression of GCP II as measured by quantitative Western blots in a regionally selective manner (Flores and Coyle, in press). Although we did not find any correlation between antipsychotic medication exposure and GCP II mRNA levels in this study, it is possible that subtle differences in drug exposure might also account for the differences between the two studies.

In summary, we have found that GCP II mRNA is expressed prominently by glia, probably astrocytes. GCP II

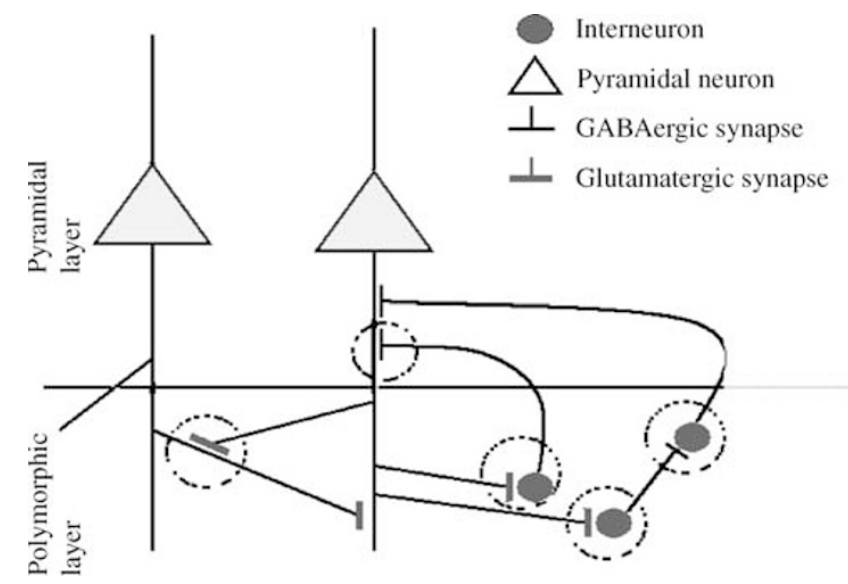

Figure $\mathbf{6}$ Schematic representation of synapses made between pyramidal neurons and interneurons in the polymorphic layer of CA3 in the hippocampus. The CA3 polymorphic layer is comprised of basal dendrites from pyramidal neurons, interneurons and glia. Principal axons of the CA3 pyramidal neurons give rise to primary branches, many of which remain in the polymorphic layer and arborize extensively. The majority of contacts made between the CA3 pyramidal neurons and GABAergic neurons are in the polymorphic layer. gene expression is significantly different in the polymorphic layer of CA3 in schizophrenia, the CA3 region being one that has repeatedly been implicated in the pathophysiology of schizophrenia. Our results further support the finding that hydrolysis of NAAG is disrupted in the hippocampus of patients with schizophrenia.

\section{MATERIALS AND METHODS}

\section{Brain Collection}

Post-mortem brains were obtained from the Office of the Chief Medical Examiner in Washington, DC. Coronal slabs of the entire rostral-caudal extent of a hemisected brain $(1-1.5 \mathrm{~cm}$ thick) were fresh frozen at the time of autopsy in a 50:50 mixture of isopentane and dry ice as previously described (Kleinmn et al, 1995). The coronal slabs were bagged and stored at $-80^{\circ} \mathrm{C}$ until further dissection could be conducted. The DLPFC, located along the middle one-third of the middle frontal gyrus, was trimmed while frozen into a wedge-shaped block along the superior frontal sulcus/middle frontal gyrus of all cases. Brodmann's area 46 (BA 46) of the DLPFC was identified through Nissl staining according to defined cytoarchitectural criteria (Rajkowska and Goldman-Rakic, 1995). Blocks (2-3) of the rostral mesial temporal lobe were sectioned from the amygdala through the body of the hippocampus; sections were stained and anatomically matched at the rostral midbody level of the hippocampus (Rosene and van Hoesen, 1987). The cryostat sections (14 m thick) from both regions were mounted on gelatin-subbed slides and stored at $-80^{\circ} \mathrm{C}$.

Tissue from Rhesus macaque monkeys was collected from normal adults according to NIH guidelines. Animals were perfused with normal saline under ketamine anesthesia. After removal of the brain from the skull, coronal slabs of brain were serially blocked in $\sim 1 \mathrm{~cm}$ increments, frozen in a 50:50 dry ice-isopentane slurry and stored at $-80^{\circ} \mathrm{C}$. Sections were cut by cryostat $(14 \mu \mathrm{m})$ in the coronal plane, collected on subbed slides and stored at $-80^{\circ} \mathrm{C}$. Sections from the monkey brains containing the upper and lower banks of the principal sulcus (primate DLPFC, Area 46) and anterior hippocampus were used to compare regional and cellular expression patterns of GCP II in monkeys and humans (Paxinos et al, 2000).

For the human studies, cohort 1 was used to perform the analysis of GCP II mRNA in the DLPFC, while cohort 2 was used in a separate experiment to examine the GCP II mRNA expression in the hippocampus. Most subjects were included in both cohorts (Table 1). Cohort 1 included post-mortem brains from 29 individuals ranging in age from 18 to 83 years, while brains of 21 individuals ranging in age from 23 to 81 years were used in cohort 2. Each cohort consisted of two groups, patients with schizophrenia and normal controls. Cases were screened by police and/or by telephone interviews of family members for a history of medical and/or psychiatric illnesses including substance abuse. The human brains used were free of neuropathological changes as determined by gross and microscopic examination. Bielschowsky's silver stain was performed on multiple cortical areas to exclude neuritic pathology. Diagnostic groups within each cohort were matched as 
closely as possible for race, gender, age, $\mathrm{pH}$, and postmortem interval (PMI).

\section{pH Determination}

In each case, a frozen section of lateral cerebellum was pulverized over dry ice and $500 \mathrm{mg}$ of the tissue was weighed. The sample was homogenized for $15 \mathrm{~s}$ in $5 \mathrm{ml}$ of $\mathrm{dH}_{2} \mathrm{O}$ using a $7 \mathrm{~mm}$ diameter generator probe with a processing range from 0.25 to $10 \mathrm{ml}$ (Omni International, Gainesville, VA) attached to a handheld tissue homogenizer (model Omni TH, Omni International Inc., Gainesville, VA). Tissue $\mathrm{pH}$ was measured on a model $370 \mathrm{PerpHeCT} \mathrm{pH} / \mathrm{ISE}$ meter (AT1 Orion Analytical Technology Inc., Boston, MA) equipped with a PerpHeCT Ross glass electrode.

\section{Riboprobe Design}

The human GCP II cDNA that was provided from the laboratory of Dr Joseph Coyle was isolated from human LNCaP cell line (Luthi-Carter et al, 1998a, b). The cDNA is a $2.5 \mathrm{~kb}$ insert in the pcDNA3 plasmid (Invitrogen) between the BamHI and XbaI sites. The antisense and sense templates were linearized using HindIII and ApaI, respectively. ${ }^{35} \mathrm{~S}$-UTP-labeled riboprobes with specific activities between $1.76 \times 10^{9}$ and $2.39 \times 10^{9} \mathrm{cpm} / \mu \mathrm{g}$ were synthesized using an in vitro transcription kit (Riboprobe Systems, Promega, Madison, WI) with SP6 polymerase and T7 polymerase to generate the antisense and sense riboprobes, respectively.

\section{In situ Hybridization}

Two $14 \mu \mathrm{m}$ sections per region per case were used in each in situ hybridization experiment. Tissue sections were fixed, acetylated, delipidated and dehydrated, then hybridized with ${ }^{35} \mathrm{~S}$-UTP-labeled riboprobes overnight at $55^{\circ} \mathrm{C}$ as previously described (Whitfield et al, 1990). Control sections of PFC and hippocampus were hybridized with radiolabeled sense strand in the same experiment and under the same conditions. Following the in situ procedure, slides were apposed to Kodak autoradiographic film (Biomax) for 3-4 weeks along with ${ }^{14} \mathrm{C}$ standards (American Radiolabeled Chemicals, Inc., St Louis, MO). Once the autoradiographic films were developed, all the slides were dipped in photographic emulsion (Kodak Emulsion NTB-2), dried and subsequently developed in D-19 developer (Kodak) after 12-24 weeks. To maximize the silver grain signal for cellular analysis, additional slides of human hippocampus and primate PFC and hippocampus were immediately dipped in photographic emulsion after the in situ hybridization.

\section{Image Analysis}

Autoradiographic films were scanned using a HewlettPackard Scanjet Plus flatbed at $300 \mathrm{dpi}$ resolution. The autoradiographic images were analyzed using the $\mathrm{NIH}$ Image software version v.1.61. (Rasband, NIH). Quantification of optical densities was performed blind to diagnosis in the DLPFC and regions in the hippocampal formation including the dentate gyrus, CA4, CA3, CA1, subiculum, and

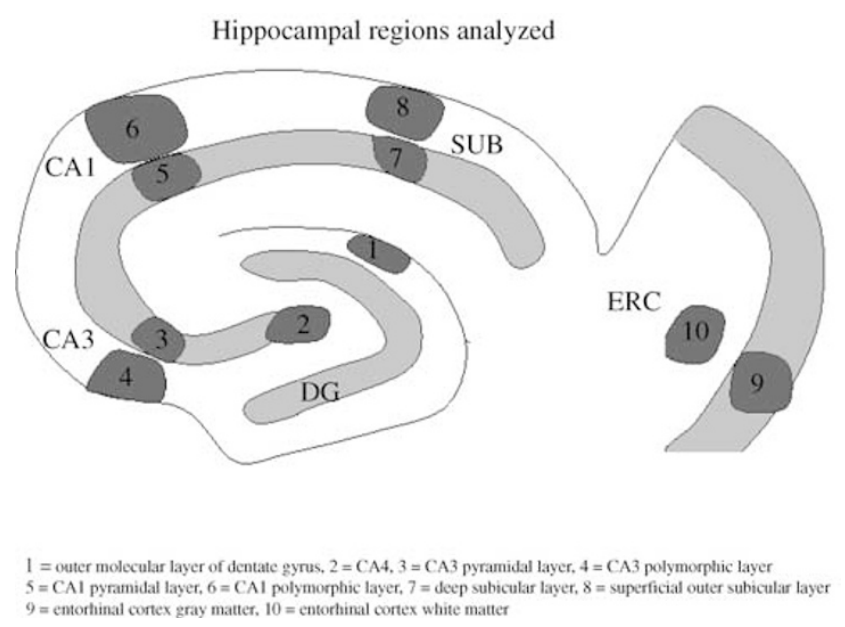

Figure 7 Schematic diagram illustrating regions where measurements were made for GCP II mRNA.

entorhinal cortex. In the DLPFC and ERC, measurements were taken from gray and white matter areas. For gray matter, sample areas traversed the entire cortex; for the white matter, samples were taken from the subcortical region. Within the Ammon's horn, areas were sampled from the region of highest signal intensity, the polymorphic layer (comprised of the stratum oriens and alveus), and the region of lowest signal intensity, the pyramidal layer (Figure 7). In the dentate gyrus, samples were taken from regions of highest signal that corresponded to the molecular layer. $\mathrm{A}{ }^{14} \mathrm{C}$ standard curve was plotted for each cohort in order to calculate $\mu \mathrm{Ci} / \mathrm{g}$ of GCP II mRNA measured in each sample area. A total of 10 areas of interest were sampled from each of two slides available for each case. An average was obtained from the two slides for each area of interest. In four cases, it was not possible to sample every region due to inadvertent damage while processing the tissue.

\section{Statistical Analysis}

The demographic variables $\mathrm{pH}, \mathrm{PMI}$, and age were compared between cohorts using $t$-tests. Correlation with average GCP II mRNA levels in areas sampled with the $\mathrm{pH}$, PMI, age, and lifetime exposure to antipsychotic medication were run with a Spearman Rank Order correlation. The effect of diagnosis on GCP II mRNA levels in specific regions was analyzed using a mixed model ANOVA with diagnosis as the between group factor and brain area as the within group factor. Significant findings were further analyzed using post hoc $t$-tests. GCP II mRNA values outside two SDs away from the mean for each area were considered outliers and were not included in the statistical analyses.

\section{ACKNOWLEDGEMENTS}

We thank Dr Juraj Cervenak, Mrs Yeva Snitkovsky, and Dr Richard C Saunders for technical and material assistance. There are no conflicts of interest that may potentially bias any of the authors. 


\section{REFERENCES}

Amaral D, Insausti R (1990). Hippocampal formation. In: Paxinos G (ed). The Human Nervous System. Academic Press: San Diego, CA. pp 711-756.

Bachus SE, Hyde TM, Shannon Weickert C, Shashidharan P, Herman MM, Kleinman JE (1996). Reduced level of excitatory amino acid transporter 3 mRNA in hippocampus of schizophrenics. Soc Neurosci Abstract 26: 112.

Berger UV, Luthi-Carter R, Passani LA, Elkabes S, Black I, Konradi C et al (1999). Glutamate carboxypeptidase II is expressed by astrocytes in the adult rat nervous system. J Comp Neurol 415: 52-64.

Bertolino A, Nawroz S, Mattay VS, Barnett AS, Duyn JH, Moonen CT et al (1996). Regionally specific pattern of neurochemical pathology in schizophrenia as assessed by multislice proton magnetic resonance spectroscopic imaging. Am J Psychiatry 15: $1554-1563$.

Cartmell J, Monn JA, Schoepp DD (2000). Attenuation of specific PCP-evoked behaviors by the potent mGlu2/3 receptor agonist, LY379268 and comparison with the atypical antipsychotic, clozapine. Psychopharmacology (Berl) 148: 423-429.

Coyle JT (1997). The nagging question of the function of $\mathrm{N}$ acetylaspartylglutamate. Neurobiol Dis 4: 231-237.

Dean B, Scarr E, Bradbury R, Copolov D (1999). Decreased hippocampal (CA3) NMDA receptors in schizophrenia. Synapse 32: 67-69.

Deicken RF, Pegues M, Amend D (1999). Reduced hippocampal Nacetylaspartate without volume loss in schizophrenia. Schizophr Res 37: 217-223.

Du F, Okuno E, Whetsell Jr WO, Kohler C, Schwarcz R (1990). Distribution of quionolinic acid phosphoribosyltransferase in the human hippocampal formation and parahippocampal gyrus. J Comp Neurol 295: 71-82.

Eastwood SL, Harrison PJ (1995a). Decreased synaptophysin in the medial temporal lobe in schizophrenia demonstrated using immunoautoradiography. Neuroscience 69: 339-343.

Eastwood SL, Harrison PJ (1999). Detection and quantification of hippocampal synaptophysin messenger RNA in schizophrenia using autoclaved, formalin-fixed, paraffin wax- embedded sections. Neuroscience 93: 99-106.

Eastwood SL, McDonald B, Burnet PW, Beckwith JP, Kerwin RW, Harrison PJ (1995b). Decreased expression of mRNAs encoding non-NMDA glutamate receptors GluR1 and GluR2 in medial temporal lobe neurons in schizophrenia. Brain Res Mol Brain Res 29: 211-223.

Harris KM, Rosenberg PA (1993). Localization of synapses in rat cortical cultures. Neuroscience 53: 495-508.

Ishizuka N, Cowan WM, Amaral D (1995). A quantitative analysis of the dendritic organization of pyramidal cells in the rat hippocampus. J Comp Neurol 362: 17-45.

Javitt DC, Zukin SR (1991). Recent advances in the phencyclidine model of schizophrenia. Am J Psychiatry 148: 1301-1308.

Kleinmn JE, Hyde TM, Herman MM (1995). Methodological issues in the neuropathology of mental illness. In: loom FE, Kupfer DJ (eds). Psycopharmacology: The Fourth Generation of Progress. Raven Press: New York. pp 859-864.

Krystal JH, Karper LP, Seibyl JP, Freeman GK, Delaney R, Bremner JD et al (1994). Subanesthetic effects of the noncompetitive NMDA antagonist, ketamine, in humans. Psychotomimetic, perceptual, cognitive, and neuroendocrine responses. Arch Gen Psychiatry 51: 199-214.

Lahti AC, Koffel B, LaPorte D, Tamminga CA (1995). Subanesthetic doses of ketamine stimulate psychosis in schizophrenia. Neuropsychopharmacology 13: 9-19.

Lahti AC, Weiler MA, Tamara Michaelidis BA, Parwani A, Tamminga CA (2001). Effects of ketamine in normal and schizophrenic volunteers. Neuropsychopharmacology 25: 455-467.

Li XG, Somogyi P, Buzsaki G (1994). The hippocampal CA3 network: An in vivo intracellular labeling study. J Comp Neurol 339: 181-208.

Luthi-Carter R, Barczak AK, Speno H, Coyle JT (1998a). Hydrolysis of the neuropeptide $\mathrm{N}$-acetylaspartylglutamate (NAAG) by cloned human glutamate carboxypeptidase II. Brain Res 795: 341-348.

Luthi-Carter R, Barczak AK, Speno H, Coyle JT (1998b). Molecular characterization of human brain $\mathrm{N}$-acetylated alpha-linked acidic dipeptidase (NAALADase). J Pharmacol Exp Ther 286: $1020-1025$.

McBain CJ, Fisahn A (2001). Interneurons unbound. Nat Rev Neurosci 2: 11-18.

Moghaddam B, Adams BW (1998). Reversal of phencyclidine effects by a group II metabotropic glutamate receptor agonist in rats. Science 281: 1349-1352.

Neale JH, Bzdega T, Wroblewska B (2000). N-Acetylaspartylglutamate: the most abundant peptide neurotransmitter in the mammalian central nervous system. J Neurochem 75: 443-452.

Passani LA, Vonsattel JP, Coyle JT (1997). Distribution of $\mathrm{N}$ acetylaspartylglutamate immunoreactivity in human brain and its alteration in neurodegenerative disease. Brain Res 772: 9-22.

Paxinos G, Huang X, Toga AW (2000). The Rhesus Monkey Brain in Stereotaxic Coordinates. New York: Academic Press. Figure 66.

Porter RH, Eastwood SL, Harrison PJ (1997). Distribution of Kainate receptor subunit mRNAs in human hippocampus, neocortex and cerebellum, and bilateral reduction of hippocampal GluR6 and KA2 transcripts in schizophrenia. Brain Res 751: 217-231.

Rajkowska G, Goldman-Rakic PS (1995). Cytoarchitectonic definition of prefrontal areas in the normal human cortex: I. Remapping of areas 9 and 46 using quantitative criteria. Cereb Cortex 5: 307-322.

Renno WM, Lee JH, Beitz AJ (1997). Light and electron microscopic immunohistochemical localization of $\mathrm{N}$-acetylaspartylglutamate (NAAG) in the olivocerebellar pathway of the rat. Synapse 26: 140-154.

Rosene DL, van Hoesen GW (1987). The hippocampal formation of the primate brain. A review of some comparative aspects of cytoarchitecture and connections. In: Jones EG, Peters A (eds). Cerebral Cortex, Vol 6. Plenum Press: New York. pp 273-280.

Sekiguchi M, Wada K, Wenthold RJ (1992). N-acetylaspartylglutamate acts as an agonist upon homomeric NMDA receptor (NMDAR1) expressed in Xenopus oocytes. FEBS Lett 311: 285-289.

Semple CA, Devon RS, Le Hellard S, Porteous DJ (2001). Identification of genes from a schizophrenia-linked translocation breakpoint region. Genomics 73: 123-126.

Sik A, Tamamaki N, Freund TF (1993). Complete axon arborization of a single CA3 pyramidal cell in the rat hippocampus, and its relationship with postsynaptic parvalbumin-containing interneurons. Eur J Neuroscience 5: 1719-1728.

Slusher BS, Robinson MP, Tsai G, Simmins ML, Richards SS, Coyle JT (1990). Rat brain $N$-acetyled alpha linked acidic dipeptidase activity: purification and immunologic characterization. J Biol Chem 265: 21297-21301.

Slusher BS, Tsai G, Yoo G, Coyle JT (1992). Immunocytochemical localization of the $\mathrm{N}$-acetyl-aspartyl-glutamate (NAAG) hydrolyzing enzyme $\mathrm{N}$-acetylated alpha-linked acidic dipeptidase (NAALADase). J Comp Neurol 315: 217-229.

Stauch-Slusher B, Robinson MB, Forloni G, Tsai G, Coyle JT (1989). The effects of $N$-acetylated- $1 \alpha$-linked acidic dipeptidase (NAALADase) inhibitors on $\left[{ }^{3} \mathrm{H}\right] \mathrm{NAAG}$ catabolism in vivo. Neurosci Lett 100: 295-300. 
Trombley PQ, Westbrook GL (1990). Excitatory synaptic transmission in cultures of rat olfactory bulb. J Neurophysiol 64: 598-606.

Tsai G, Coyle JT (2002). Glutamatergic mechanisms in schizophrenia. Annu Rev Pharmacol Toxicol 42: 165-179.

Tsai G, Passani LA, Slusher BS, Carter R, Baer L, Kleinman JE et al (1995). Abnormal excitatory neurotransmitter metabolism in schizophrenic brains. Arch Gen Psychiatry 52: 829-836.

Tsai G, Stauch BL, Vornov JJ, Deshpande JK, Coyle JT (1990). Selective release of $\mathrm{N}$-acetylaspartylglutamate from rat optic nerve terminals in vivo. Brain Res 518: 313-316.

Webster MJ, Shannon Weickert C, Herman MM, Hyde TM, Kleinman JE (2001). Synaptophysin and GAP-43 mRNA levels in the hippocampus of subjects with schizophrenia. Schizophr Res 49: 89-98.

Westbrook GL, Mayer ML, Namboodiri MA, Neale JH (1986). High concentrations of $\mathrm{N}$-acetylaspartylglutamate (NAAG) selectively activate NMDA receptors on mouse spinal cord neurons in cell culture. J Neurosci 6: 3385-3392.

Whitfield HJ, Brady LS, Smith MA, Mamalaki E, Fox RJ, Herkenham M (1990). Optimization of cRNA probe in situ hybridization methodology for localization of glucocorticoid receptor mRNA in rat brain: a detailed protocol. Cell Mol Neurobiol 10: 145-157.

Williamson LC, Neale JH (1988a). Ultrastructural localization of $\mathrm{N}$ acetylaspartylglutamate in synaptic vesicles of retinal neurons. Brain Res 456: 375-381.

Williamson LC, Neale JH (1988b). Calcium-dependent release of $\mathrm{N}$ acetylaspartylglutamate from retinal neurons upon depolarization. Brain Res 475: 151-155.

Wroblewska B, Santi MR, Neale JH (1998). $N$-acetylaspartylglutamate activates cyclic AMP-coupled metabotropic glutamate receptors in cerebellar astrocytes. Glia 24: 172-179. 